\title{
CAPITAL SOCIAL E QUALIDADE DE VIDA
}

Hemerson Luiz Pase

\begin{abstract}
Resumo
Este artigo discute a relação entre cultura política e desenvolvimento socioeconômico, fazendo um resgate histórico do desenvolvimento, estabelecendo as diferentes matrizes ocupacionais do território do Rio Grande do Sul. A hipótese central retoma as formulações clássicas afirmando que quanto maior o estoque de capital social maior o desenvolvimento socioeconômico, razão pela qual as políticas públicas devem ser estruturadas no sentido de estimulá-lo. A metodologia utiliza informações empíricas que definem confiança, reciprocidade e solidariedade como indicadores de capital social que é utilizado como variável independente do IDESE, indicador de desenvolvimento socioeconômico. Os resultados indicam a pertinência da teoria de Putnam, afirmando que existe uma relação proporcional entre o capital social e o desenvolvimento socioeconômico. Os cidadãos rurais possuem um estoque de capital social superior aos urbanos, o que lhes permite sobreviver ante a hostilidade do desenvolvimento agrário.
\end{abstract}

Palavras-chave: Cultura Política; Desenvolvimento; Políticas Públicas; Rio Grande do Sul; Brasil.

\begin{abstract}
This article discusses the relationship between political culture and socioeconomic development, making a historical development, establishing the different matrices of the occupational area of Rio Grande do Sul. The central hypothesis takes the classical formulations stating that the higher the stock of social capital the greater will be socioeconomic development, which is why public policy should be structured in order to stimulate it. The methodology uses empirical data that define trust, reciprocity and solidarity as indicators of social capital that is used as the independent variable of IDESE, an indicator of socioeconomic development. The results indicate the relevance of Putnam's theory, saying that there is a proportional relationship between social capital and socioeconomic development. Rural citizens have a stock of social capital above the city, which allows them to survive against the hostility of agricultural development.
\end{abstract}

Keywords: Political Culture; Development; Public Policy; Rio Grande do Sul; Brazil.

\section{Introdução}

A importância da cultura política para os processos de desenvolvimento econômico e consolidação democrática tem espaço na literatura científica principalmente depois dos estudos de Robert Putnam, cuja pesquisa define a determinação do desenvolvimento diferenciado a partir do capital social acumulado pelas sociedades. 
O objetivo deste trabalho é aprofundar a compreensão a respeito das condições que proporcionaram a emergência de desigualdades regionais que marcam o desenvolvimento socioeconômico do Rio Grande do Sul, principalmente no que tange ao espaço rural. Existem inferências sobre a relevância da cultura política para o processo de desenvolvimento territorial e empoderamento cidadão, neste trabalho pretende-se investigar se esta relação é efetiva. Não obstante, almeja-se identificar se intervenções na perspectiva de estimular capital social podem alterar cursos históricos, aparentemente definidos, de desenvolvimento socioeconômico.

A hipótese de trabalho afirma que o investimento em políticas públicas específicas, de constituição de cooperação e confiança recíproca entre os cidadãos, constitui e/ou desenvolve e aprimora capital social, cuja existência contribui decisivamente para minimizar as desigualdades sociais e regionais e estimular o desenvolvimento equitativo e sustentável, através da melhoria da qualidade de vida.

A metodologia utilizada recolhe os resultados do projeto de pesquisa "Capital social e desenvolvimento regional: a importância do capital social no desenvolvimento territorial do COREDE Nordeste" (2004), além das informações obtidas através de entrevistas realizadas com associados da Cooperativa de Crédito Rural com Interação Solidária - CRESOL, com sede em Sananduva - RS. A confiança, solidariedade e reciprocidade serão indicadores de existência de capital social, que será considerado variável independente em relação ao desenvolviemnto socioeconômico, medido pelo Índice de Desenvolvimento Socioeconômico - IDESE.

Antes de apresentar as seções do artigo é necessário explicitar o que são os COREDEs, o IDESE e a CRESOL.

Os Conselhos Regionais de Desenvolvimento - COREDEs, foram criados oficialmente pela Lei 10.283 de 17 de outubro de 1994 , e são um fórum de discussão e decisão a respeito de políticas e ações que visam o desenvolvimento regional do Rio Grande do Sul. Seus principais objetivos são a promoção do desenvolvimento regional harmônico e sustentável; a integração dos recursos e das ações do governo na região; a melhoria da qualidade de vida da população; a distribuição equitativa da riqueza produzida; o estímulo à permanência do homem na sua região; e a preservação e a recuperação do meio. Atualmente o Estado possui 28 Conselhos Regionais de Desenvolvimento (ESTADO DO RIO GRANDE DO SUL, 2011).

O IDESE é um índice sintético, inspirado no IDH, que abrange um conjunto amplo de indicadores sociais e econômicos classificados em quatro blocos temáticos: Educação; Renda; Saneamento e Domicílios; Saúde. O IDESE varia de zero a um e, assim como o IDH, permite que se classifique o Estado, os municípios ou os COREDEs em três níveis de desenvolvimento: baixo (índices até 0,499 ), médio (entre 0,500 e 0,799 ) ou alto (maiores ou iguais que 0,800$)(\mathrm{FEE}, 2012)$. 
A Cooperativa de Crédito Rural com Interação Solidária - CRESOL é formada por agricultores familiares e atua no crédito rural e/ou agropecuário vinculado, principalmente, ao Programa de Fortalecimento da Agricultura Familiar - PRONAF, financiado pelo Governo Federal.

Este artigo está organizado em três partes, sendo que na primeira aborda-se o capital social, definindo minimamente sua matriz histórica e teórica, destacando o trabalho de Robert Putnam sobre a Itália, cuja matriz tem sido aplicada para desvendar as desigualdades sociais e territoriais do Rio Grande do Sul.

$\mathrm{Na}$ segunda parte discute-se a relação entre a teoria social e o desenvolvimento, destacando as características do desenvolvimento brasileiro e, principalmente gaúcho, marcado pela contradição da concentração de riqueza e oportunidades de acesso a bens e recursos públicos versus a socialização da pobreza e exclusão.

Na terceira parte apresentam-se resultados das pesquisas empíricas, na perspectiva de verificar a veracidade da hipótese de trabalho e apontam-se algumas recomendações estimuladas pela análise.

É importante ressalvar que o artigo utiliza dados e informações com temporalidade datada, em razão de objetivar o registro dos debates ocorridos no seminário ocorrido em 2005. Não obstante, nas considerações finais são apontados alguns elementos empíricos contemporâneos que evidenciam a pertinência da análise.

\section{Capital Social}

O capital social é um conceito que considera as características culturais, de existência de confiança, reciprocidade e solidariedade na sociedade civil, vitais para o aperfeiçoamento da democracia, das comunidades, das pessoas e inclusive da sociedade política (PUTNAM e GOSS, 2002).

Precursor a utilizar o conceito de capital social, o filósofo francês Pierre Bourdieu estendeu-o para além dos limites tradicionalmente econômicos, aplicando-o a dimensões não materiais e simbólicas, embora possibilitadoras de acesso a recursos econômicos. Para Bourdieu, "O capital social é constituído pelo conjunto de recursos atuais ou potenciais que estão ligados à posse de uma rede durável de relações mais ou menos institucionalizadas de conhecimento e reconhecimento" (1980, p. 2).

James Coleman é um dos fundadores do conceio de capital social, cuja definição considera a possibilidade de facilitar a ação de diferentes tipos de atores sociais.

Assim como outras formas de capital, o capital social é produtivo, possibilitando a realização de certos objetivos que seriam inalcançáveis se ele não existisse [...]. Por exemplo, 
um grupo cujos membros demonstrem confiabilidade e que depositem ampla confiança uns nos outros é capaz de realizar muito mais do que outro grupo que careça de confiabilidade e confiança [...]. Numa comunidade rural [...] onde um agricultor ajuda o outro a enfardar o seu feno e onde os implementos agrícolas são reciprocamente emprestados, 0 capital social permite a cada agricultor realizar o seu trabalho com menos capital físico sob a forma de utensílios e equipamento (COLEMAN, 1990, p. 302, 304 e 307, apud PUTNAM, 2000, p. 177).

Coleman trabalha com a teoria da escolha racional na qual insere o conceito de capital social, cuja formulação permite-o articular comportamentos individuais, organizacionais e sociais na explicação da ação social.

A partir da obra de Robert Putnam o conceito de capital social obterá popularidade entre os teóricos, bem como entre os meios de comunicação, instituições e gestores públicos. O autor insere o capital social como categoria heurística para explicar os problemas da ação coletiva, cuja solução supera a proposição dos seguidores da teoria dos jogos e do individualismo metodológico. Para eles a ação coletiva é resolvida através de um cálculo racional onde os participantes tomam suas decisões, com base numa análise em termos de custo e benefício, cujos resultados normalmente são subótimos. Isto ocorre em razão de que os participantes desconfiam uns dos outros, materializando este sentimento em suas decisões. A desconfiança pode ser abrandada quando ocorrem várias rodadas de jogos com regras claras e respeitadas, no entanto nada garante sua superação pela confiança (conforme "dilema do prisioneiro") (PUTNAM, 2000).

Para Putnam a teoria dos jogos explica em grande medida a ação coletiva, no entanto vários processos sociais possuem a lógica da confiança, onde o ator decide crendo, confiando no outro. Nestes casos a decisão do indivíduo não visa necessariamente, um benefício individual imediato, e sim o benefício da comunidade, cuja fonte é a confiança que, mesmo no futuro, o outro/outros indivíduos farão o mesmo. Esta lógica baseia-se numa rede social que possui regras e normas claras com sanções proibitivas para os desertores. O processo social que produz como resultado o bem comum ou o bem de uma coletividade, baseado na confiança, reciprocidade e solidariedade é definido por Putnam como capital social.

Em seu texto sobre o processo de regionalização institucional do governo Italiano, Putnam pesquisa a diferença do desempenho institucional encontrado entre as administrações regionais, ao longo dos 20 anos após sua implementação em 1970. A principal constatação é que as administrações no Centro e Norte da Itália apresentaram melhor desempenho que as do Sul. As causas destas diferenças são tradições cívicas, que teriam acumulado maior quantidade de capital social naquelas regiões, constituindo uma densa rede. 
As diferenças entre o Norte e o Sul, em relação à consolidação institucional e o desenvolvimento econômico, tem como base o capital social construído de forma diferenciada durante a história. A diferença fundamental ocorre na forma de organização das relações sociais: no Norte estabeleceu-se historicamente uma rede horizontal de relações sociais formada por associações com vários objetivos e que congregavam um contingente considerável da população regional. No Sul, ao contrário, estabeleceram-se relações sociais verticalizadas e hierarquizadas que, segundo o autor, originam-se do período da fundação do império Normando.

Putnam afirma categoricamente que as comunidades do Centro e Norte italianos não se tornaram cívicas porque eram ricas, e sim o contrário, tornaram-se ricas porque eram cívicas. O capital social incorporado em normas e redes de engajamento cívico parece ser uma pré-condição para o desenvolvimento econômico, bem como para a eficiência dos governos.

O autor afirma que o capital social é um processo histórico e cultural independente das instituições que, no entanto, pode ser impulsionado a partir destas. As maiores lições do caso italiano são as seguintes: "[...] o contexto social e a história condicionam profundamente o desempenho das instituições [...] mudando-se as instituições formais pode-se mudar a prática política [...] a história institucional costuma evoluir lentamente" (PUTNAM, 2000, p. 191 e 193).

No caso italiano o capital social possibilitou o engajamento cívico e a participação social e política o que, por sua vez, construíu instituições democráticas e um sistema de governo democrático, bem como impulsionou o desenvolvimento econômico. Este engajamento cívico, para Putnam, desenvolve-se a partir da participação em associações horizontais, de grupos de iguais tais como clubes de futebol, associações de moradores, confrarias, corais, etc. Nestes espaços os cidadãos identificam-se e socializam um sentimento de cumplicidade e confiança neles próprios e nas regras que criam. O capital social contribui para aumentar a eficiência da sociedade e facilitar ações coordenadas.

Em obra sobre os Estados Unidos da América, Putnam (2000) desenvolve a tese de que a mudança de hábitos diminuiu o estoque de capital social da sociedade americana. A pujante vida associativa que foi fundamental para o sucesso do capitalismo norteamericano estaria em declínio na primeira metade do século XIX. Para Putnam a apatia dos norteamericanos em relação à democracia, materializados pelos elevados índices de não comparecimento às urnas, ocorre em razão do declínio das redes de engajamento cívico que marcaram sua história.

Para Putnam a diferença da natureza associativa tem razões culturais. A superioridade econômica dos Estados Unidos, em relação ao restante da América, comprova esta tese. A tradição horizontal comunitária britânica foi herdada pelos norte americanos, ao passo que a América Latina recebeu como dote a verticalidade Ibérica. Max Weber (2005) já destacara o papel da 
ética protestante na estruturação de redes horizontais de colaboração, diferente das culturas verticalizadas de tradição católica. Soares (1993) também afirma que a influência da tradição religiosa é um dos elementos importantes para explicar as diferenças de desenvolvimento social e econômico entre os EUA e o restante da América.

Putnam trabalha utilizando as escalas regional e nacional para avaliar o efeito do capital social no desenvolvimento econômico e político, diferente de Coleman e Bourdieu que tratam com uma dimensão microssocial do indivíduo e da família. Não obstante a definição de capital social de Putnam apoia-se claramente na concepção de confiança, de normas e redes que facilitam a colaboração para o benefício mútuo de Coleman.

As normas de reciprocidade generalizada alimentam um sentimento de confiança, categorias centrais para o conceito de capital social, que influencia no desempenho político e econômico. Tais normas implicam na crença, dos membros da comunidade, que o comportamento altruísta do presente, que contribui para o bem estar, será retribuído no futuro. Estas redes de engajamento cívico robustecem as normas de reciprocidade, cuja influência produz sanções para aqueles que não retribuem tornando-se eficazes na medida em que a informação sobre a confiabilidade é comunicada através das redes.

Putnam, ao lado de Coleman, procura demonstrar as condições sob as quais as instituições públicas conseguem mobilizar os recursos sociais para alcançar um grau elevado de bem estar coletivo.

Ao longo da história [...] as normas e os sistemas de participação cívica promoveram o crescimento econômico, em vez de inibi-lo. Tal efeito continua até hoje. Nas duas décadas transcorridas desde a criação dos governos regionais, as regiões cívicas cresceram mais rápido do que as regiões onde há menos associações e mais hierarquia [...] o capital social, corporificado em sistemas horizontais de participação cívica, favorece o desempenho do governo e da economia, e não o oposto: sociedade forte, economia forte; sociedade forte, Estado forte (PUTNAM, 2000, p. 186).

A partir de suas pesquisas sobre os EUA, Putnam sofrerá muitas críticas oriundas principalmente de teóricos ligados ao neoinstitucionalismo, a principal delas afirma seu determininismo histórico e cultural (EVANS, 1996) e no afã de comprovar esta afirmação, caem em outra normatividade que é a da afirmação do determinismo institucionalista. O debate central parece estar localizado na identificação do princípio último (como diriam os filósofos présocráticos) criador, ou gerador: o que é mais importante para garantir a previsibilidade da ação coletiva - capital social ou instituições? É possível que nenhuma das formulações seja completamente verdadeira, é possível que as 
duas situações possam conviver e, é provável que a determinação dependa do contexto social que se está analisando (BAQUERO, 2003).

O entusiasmo de teóricos e estadistas a respeito do conceito de capital social relaciona-se à sua potencialidade de estabelecer uma nova relação entre a sociedade civil e o Estado. Este conceito possibilita à ciência analisar possibilidades inovadoras de relação entre as pessoas comuns e o "poder" enquanto tal. O capital social é uma capacidade que empodera o cidadão, cuja confiança aprimora a democracia, produz desenvolvimento institucional quando constitui regras claras de comportamento com sanções para os desertores, produz desenvolvimento econômico na medida em que possibilita acesso a informações e estimula solidariedade, e constrói uma cultura política baseada em valores humanitários. Segundo Baquero

A existência de confiança não só cria um ambiente de credibilidade $e$, consequentemente, de legitimidade, como fortalece o contrato social [...]. A credibilidade de um sistema político e seu eficiente desempenho, portanto, depende do grau de confiança que as pessoas têm nas instituições [...]. Sem confiança a democracia não sobrevive (BAQUERO, 2003, 96-97 e 100).

\section{Teoria Social e Desenvolvimento}

O conceito de desenvolvimento surge no século XIX, inserido no ambiente social e intelectual da modernidade, gestada historicamente pela revolução francesa e industrial e pela constituição dos estados nacionais. $O$ ambiente intelectual era fundamentado pelos princípios liberais, cujo conteúdo sinalizava a possibilidade de progresso humano e material ilimitado (PASE, 2001).

O conceito ocupa espaço relevante na literatura a partir do final da segunda guerra mundial, cujos reflexos modificam por completo o cenário planetário. Até então o termo desenvolvimento é sinônimo de progresso, conceito que supõe determinismo histórico evolucionista no sentido do pior para o melhor, do atrasado para o moderno, do tradicional ao desenvolvido, do rural para o urbano.

Nos anos 1970 o debate sobre desenvolvimento sustentável emerge no cenário internacional, animado principalmente pela Conferência das Nações Unidas para o Ambiente Humano, realizada em Estocolmo, em 1972, onde se identifica a necessidade de associar o crescimento econômico à preservação do meio ambiente. Uma das premissas do desenvolvimento sustentável, naquele momento, foi o reconhecimento da inadequação social e ambiental do crescimento econômico em relação à manutenção do equilíbrio ambiental planetário nas sociedades contemporâneas. A satisfação das necessidades humanas, a qualidade de vida e do meio ambiente apresentaram-se como 
elementos interdependentes e, portanto, a pobreza surge como uma das principais causas da degradação da natureza.

$O$ conceito de desenvolvimento rural emerge no momento em que o termo desenvolvimento supera a noção de progresso, no contexto do final da segunda guerra mundial, quando são empreendidas políticas de reconstrução dos países destruídos materialmente e políticas de superação do subdesenvolvimento para as nações que se libertam do colonialismo.

A evolução da definição de desenvolvimento rural pode ser dividida em três períodos distintos histórica e conceitualmente. Na década de 1970 inserese no contexto de pós-segunda guerra mundial e crescente tensão da guerra fria. Seu objetivo principal era o rápido crescimento econômico capaz de incorporar o conjunto da sociedade inclusive as populações rurais, resolvendo os problemas da pobreza através da divisão da riqueza acumulada.

Na década de 1980 a característica central é o desenvolvimento social e econômico utilizando tecnologias apropriadas, cuja relação estabelece uma dependência com a indústria produtora de insumos e a indústria processadora de produtos agrícolas, além da incorporação da preocupação com sustentabilidade social, econômica e ambiental.

Na década de 1990 os elementos centrais são o desenvolvimento rural integrado e sustentável, a favor dos pobres, baseado em tecnologias apropriadas, considerando aspectos sociais e econômicos; valorização dos direitos das mulheres e outros grupos sociais minoritários; valorização da participação decisória dos mais pobres na implementação dos projetos.

As políticas de desenvolvimento rural no Brasil são implementadas prioritariamente pelo Governo Federal até a década de 1990, período em que ocorrem mudanças na racionalidade técnica, uma vez que os projetos passam a buscar equalizar objetivos, metodologia, instrumentos e público alvo. Além disso, a formulação dos projetos transforma-se passando do padrão supplydriven (orientado pela oferta) para o padrão demand-driven (orientado pela demanda), cujo significado é a formulação de projetos definidos pela necessidade das populações e/ou territórios. Neste contexto outros setores da sociedade civil começam a participar da proposição, execução e controle dos projetos de desenvolvimento rural, cuja mudança é impulsionada, de um lado, pela democratização política e, de outro, por modificações na motivação dos projetos, na forma de entender e tratar a pobreza rural e no entendimento acerca do rural, cujo conceito supera a noção de oposição ao urbano, enquanto espaço onde não há urbanização (energia, saneamento, transporte, telefonia, pavimentação, etc.) passa a implicar em território que possui um conjunto de processos sociais, econômicos e políticos inter-dependentes em relação ao urbano.

A tentativa de definir um conceito de desenvolvimento rural é empreendida no Brasil a partir de dois autores principais. José Eli da Veiga (2001), que observa as dimensões ambientais e territoriais do desenvolvimento rural destacando suas interfaces e vínculos em relação ao 
desenvolvimento em geral, e Zander Navarro (2001), para quem a noção de desenvolvimento rural restringe-se ao seu uso prático e normativo, com a finalidade de caracterizar estratégias e ações do Estado que visam alterar e/ou melhorar as condições de vida no meio rural.

É possível uma aproximação teórica ao desenvolvimento rural articulando as duas anteriores no sentido de concebê-lo como uma estratégia, porém não exclusivamente do Estado, ao mesmo tempo, vincula-se ao desenvolvimento em geral considerado, segundo os termos de Amartya Sen (2000, p. 17), como "um processo de expansão das liberdades reais que as pessoas desfrutam".

O desenvolvimento rural é um processo social e político articulado intencionalmente através de um planejamento estratégico definido claramente, no sentido de impulsionar uma dinâmica social, econômica, cultural, ambiental e política democrática, sustentável e caracterizada pela ampliação e aprofundamento da qualidade de vida da população de um determinado território rural. É proposto, implementado e financiado principalmente pelo Estado, através de seus entes federados, mas também por instituições da sociedade civil, tais como cooperativas e organizações não governamentais (ONGs).

\section{O Rio Grande do Sul}

De forma similar à segmentação italiana proposta por Putnam, o desenvolvimento do estado mais meridional do Brasil, o Rio Grande do Sul, ocorre de forma segmentada entre a metade Norte e a metade Sul. Esta cisão territorial, social e econômica tem suas origens na colônia e consolida-se durante o império e na primeira república quando a sociedade gaúcha diferencia-se na sua vocação econômica em uma sociedade agrícola, no Norte, e uma sociedade pecuária, no Sul (SINGER, 1977).

Baquero e Prá (1995) afirmam que a sociedade gaúcha é segmentada entre estancieiros, de um lado, e colonos, imigrantes, peões, posseiros, agregados e índios, de outro. O Norte contribui com o crescimento econômico, enquanto o Sul trata da gestão política do Estado, cuja dicotomia possibilita que a economia regional caracterize-se como dependente, periférica, excludente e associada voltada para a expansão das atividades agropecuárias vinculadas às atividades fabris e exportadoras do Sudeste brasileiro.

Deste mesmo prisma Alonso e Bandeira demonstram

[...] o quadro que viria a se tornar uma das características da futura configuração espacial da economia gaúcha: um norte mais dinâmico e economicamente mais diversificado e um sul de crescimento lento e de estrutura produtiva mais especializada (ALONSO e BANDEIRA, 1990, p. 74). 
As políticas do Império para o Sul do Brasil produziram um modelo de ocupação social e econômica complementar à colonial exportadora baseada na grande propriedade, e na produção de matérias primas e gêneros tropicais para exportação (PRADO JR., 1984), materializados nos ciclos econômicos do ouro, da cana-de-açúcar e do café. A região Sul foi encarregada da produção de alimentos para garantir a subsistência daquelas que se dedicavam exclusivamente à exportação, além da manutenção das fronteiras do território nacional, não é mera coincidência o grande contingente do Exército Brasileiro que foi afixado em Quartéis ao longo da fronteira brasileira no Rio Grande do Sul na divisa com a Argentina e o Uruguai.

Esta matriz ocupacional determina o tamanho das propriedades cuja distribuição ocorre de forma clientelista aos coronéis ou mandões locais que, muitas vezes eram os comandantes do exército imperial ou da guarda nacional. Esse processo inicia durante o império e se consolida na primeira república como padrão relacional entre as lideranças políticas nacionais, regionais e locais.

O clientelismo é uma relação de poder verticalizada cuja característica essencial é a troca de favores por votos. Ocorre desde o nível micro, na relação entre o líder local e os cidadãos comuns, passando pela relação entre aquele e o líder regional e/ou estadual e, por fim, chegando a influenciar a correlação de forças nacionais. Embora persista ainda hoje em alguns recantos brasileiros, tem origem na primeira república onde a capacidade de eleição de um candidato a cargo público era diretamente relacionada à sua capacidade de prestar favores (nomeação para cargos públicos, liberação de verbas, concessão de obras, títulos de posse de terras) para os seus correligionários locais e/ou regionais que, por sua vez, eram líderes, coronéis e/ou mandões, que garantiam seu poderio trocando favores (proteção, permissão de trabalhar como agregado, trabalho assalariado ou serviços públicos) por lealdade, materializada por trabalho na grande propriedade, por serviços militares e, principalmente, por votos, cujo destino obedece à sua ordem.

Segundo Queiroz (1975) no Nordeste se afirmava o alcance do poder de um coronel através da frase: "... fulano é gente do coronel cicrano...", o que demonstra o nível de subordinação dos clientes e da relação patriarcal com o mandão local. Segundo Holanda o patriarcado é "[...] um todo indivisível, cujos membros se acham associados uns aos outros, por sentimentos e deveres, nunca por interesses e idéias" (HOLANDA, 1995, p. 79). Para Queiroz o elemento determinante do poder impetrado pela relação patriarcal é garantido pelo papel desempenhado pela família.

A família tinha, pois, no centro, o casal branco e seus filhos legítimos, e uma periferia mal delineada de escravos, agregados, afilhados, na qual se incluíam as concubinas do chefe e seus filhos ilegítimos. O casamento era questão de 
grande importância; os pais escolhiam cuidadosamente as alianças ou para reforçar os laços de parentesco e resguardar a propriedade de mãos estranhas - uniões com primos, tios, etc. - ou para aumentar poder e prestígio, indo se unir a outras famílias de particular nomeada ou fortuna[...] 0 brasileiro típico, o "homem bom", era o homem da família, do seu grupo familial, de sua aldeia (QUEIROZ, 1975, p. 45).

Além dessas, somam-se as pessoas que se mantinham como clientes do coronel, cujas relações desenvolvem-se diretamente no interior da fazenda e/ou incorporam, inclusive, algumas vilas. O indivíduo que não fosse integrado a uma família dificilmente prosperava e não conseguiria ocupar cargo público.

A ocupação territorial e econômica do Rio Grande do Sul é impulsionada por quatro movimentos, dos quais três foram externos, cujos objetivos eram povoar as fronteiras, garantir o território e implantar uma economia familiar com capacidade de abastecer as regiões exportadoras com produtos de consumo interno. Segundo Gehlen e Melo, desenvolveram-se quatro correntes:

A primeira, mais antiga, formou-se no próprio território, constituindo o que ficou conhecido como Missões, ou missioneira, e teve seu ápice no século XVIII. A segunda atingiu a campanha ou pampa, no sul-sudoeste, correspondendo a quase metade do território do estado [...]. A terceira corrente, composta por açorianos, atingiu entre 1748 e 1772 o litoral e parte das terras já povoadas, próximas a Porto Alegre e, em direção ao centro do estado, a Rio Pardo [...] encontrando-se na mão-de-obra excluída pela seleção da força de trabalho resultante da industrialização em alguns países da Europa. Iniciou-se, assim, logo após a Independência, o quarto fluxo ocupatório, composto por imigrantes de economia familiar daqueles países (GEHLEN e MELO, 1997, p. 100).

Para os autores a corrente missioneira foi marcada pela miscigenação entre as culturas indígena e européia coordenada pela intervenção dos jesuítas, cuja relação propiciou a formação de mão-de-obra e o desenvolvimento da criação de gado. Os açorianos implantam a cultura do trigo no Estado apesar de não conseguiram desenvolver a produção de alimentos, no entanto se destacam na produção de artesanato, no comércio e na formação de núcleos urbanos.

A campanha foi ocupada por militares de todas as patentes, cuja função original era construir uma barreira militar para garantir o território nacional, e por portugueses aventureiros em busca de fortuna que desenvolveram a criação de gado e muares e mais tarde ovinos e a indústria 
de charque. Esta região corresponde por quase metade do território gaúcho e até o século XX é hegemonizada por grandes propriedades com criação extensiva de gado onde se desenvolve uma sociedade marcada, grosso modo, por dois tipos sociais: o latifundiário e o peão. O latifundiário é o dono da grande propriedade de terra, tem acesso às políticas do Estado e participa como cidadão votando e influenciando os processos eleitorais, além de compor majoritariamente a elite política estadual, pelo menos até meados do século XX. De outro lado, o peão trabalha para o latifundiário nas lides do gado e/ou cultiva a roça das propriedades, sua cidadania submissa não supera a condição clientelista em relação ao senhor de terras, cujas características marcantes são o patrimonialismo e o patriarcalismo.

O patrimonialismo é a estrutura de poder que trata o público de forma privada. É a utilização de bens e recursos públicos de forma a auferir resultados particulares e/ou privados. Contemporaneamente a ciência política tem substituído este termo pelo conceito de corrupção (HOLANDA, 1995).

Os imigrantes europeus adaptam-se às terras e às condições de vida da região de matos do Rio Grande do Sul, correspondente à parte Norte do Estado, limitado ao Norte por Santa Catarina e, ao Sul, pela área de passagem do relevo mais acidentado para formações onduladas ou pelo limite entre a, já destruída, floresta subtropical com araucária e as áreas de campo. Desenvolvem a produção de alimentos e produtos manufaturados de forma artesanal tais como: vinho, queijo, erva-mate, utensílios domésticos e para o cultivo da terra.

Para Baquero e Prá, a pequena propriedade, ao lado de uma agricultura diversificada e da comercialização do excedente produzido, promoveu uma maior distribuição de renda e a criação de uma rede urbana formada por pequenos centros próximos entre si, em contraste com o regime da grande propriedade latifundiária e de concentração de rendas do Sul, que congregava um número reduzido de assalariados com pouca renda.

[...] os colonos europeus tiveram um papel preponderante não só em termos de ocupação do solo, mas também, na dinamização da economia do norte do Estado e, em especial, para a criação de uma sociedade bem distinta daquela estabelecida no sul pelos pecuaristas (BAQUERO e PRÁ, 1995, p. 20).

Não obstante, somente em 1881 com a promulgação da lei Saraiva concessão de direito de votar e ser votado a estrangeiros - é que os imigrantes passam a atuar na política. Entre os alemães eram vendistas, colonos que através do escambo conseguem acumular excedentes de produção de subsistência da sociedade local e, portanto, adquirem riqueza mesmo na fase anterior à agricultura comercial, que conseguem atuar na política, embora, sua participação se limite a estabelecer a ligação entre a 
massa de pequenos proprietários e a oligarquia pecuarista de forma clientelista. Seu papel político supera a condição clientelista em relação aos líderes locais e regionais somente na segunda metade do século XX quando ocorre o advento da primeira experiência democrática moderna do país entre os anos de 1945 e 1964.

\section{A cultura importa}

Este trabalho é herdeiro teórico de dois autores que, em alguma medida, contrapõem-se. Afirma-se a tese de Putnam (2000), para quem a cultura política de uma sociedade, construída historicamente, determina o desenvolvimento social, econômico e político dos territórios. Confiança, reciprocidade e solidariedade, embasadas em normas claras e na livre e vigorosa circulação de informações definem o capital social, cuja potencialidade de obter resultados e/ou bens tangíveis é inegável, embora, muitas vezes, insuficiente.

Não obstante, aceita-se a tese de Coleman (1990) para quem as sociedades que não tenham construído capital social não podem ser condenadas ao desespero do determinismo histórico. Para o autor, o capital social pode ser impulsionado ou construído a partir de ações institucionais, principalmente do Estado.

A confiança é o indicador chave, utilizado em pesquisas empíricas, para mensurar o capital social, embora exista um debate em torno da possibilidade de sua utilização científica. A Figura 1 apresenta o índice de confiança generalizada para o conjunto do território do Corede Nordeste do Estado do RS, segmentado por local de moradia dos entrevistados: urbano ou rural. 
Figura 1

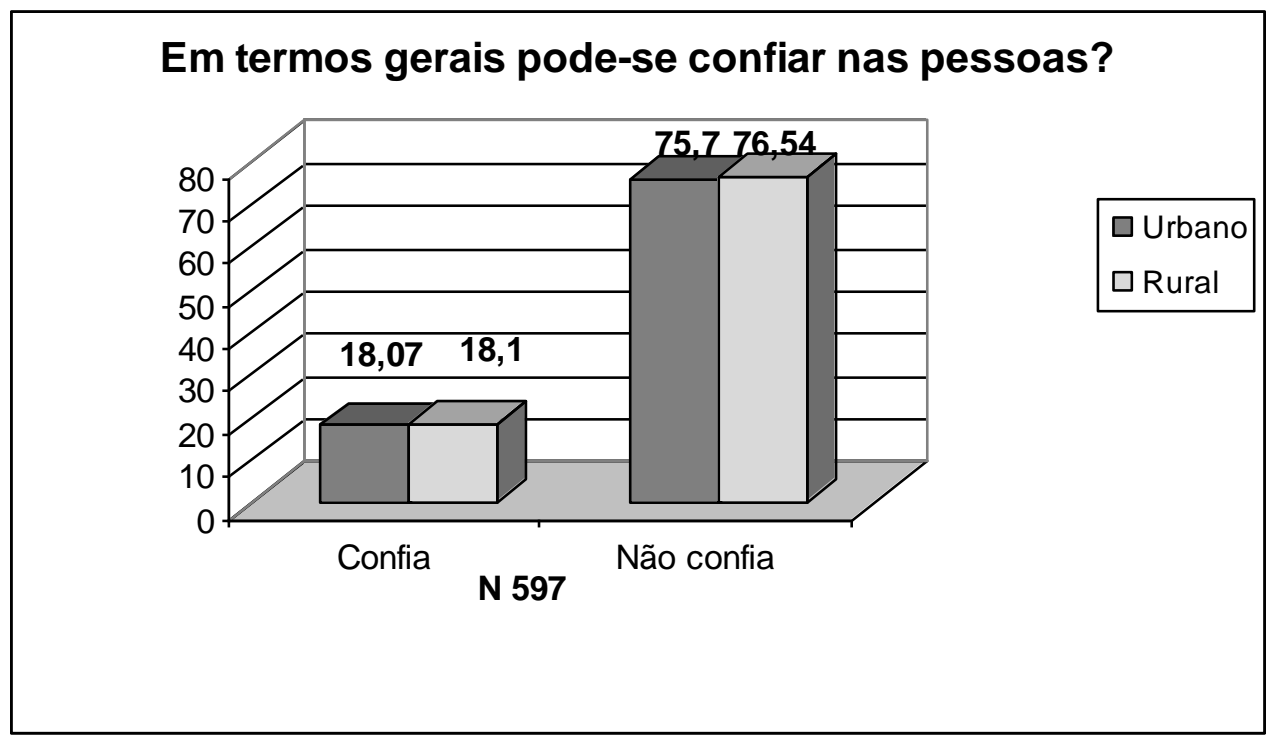

Fonte: Pase (2006).

Observa-se que o índice de confiança de $18 \%$ é bem menos expressivo que o de não confiança, $75 \%$, cuja comparação demonstra a fragilidade da confiança generalizada entre os cidadãos do território, bem como a semelhança da confiança generalizada entre cidadãos que residem no espaço urbano e rural.

Entretanto, quando considerada de forma menos aleatória e generalizada, é possível observar uma sensível diferença na confiança entre urbanos e rurais. A Figura 2 apresenta esta informação. 
Figura 2

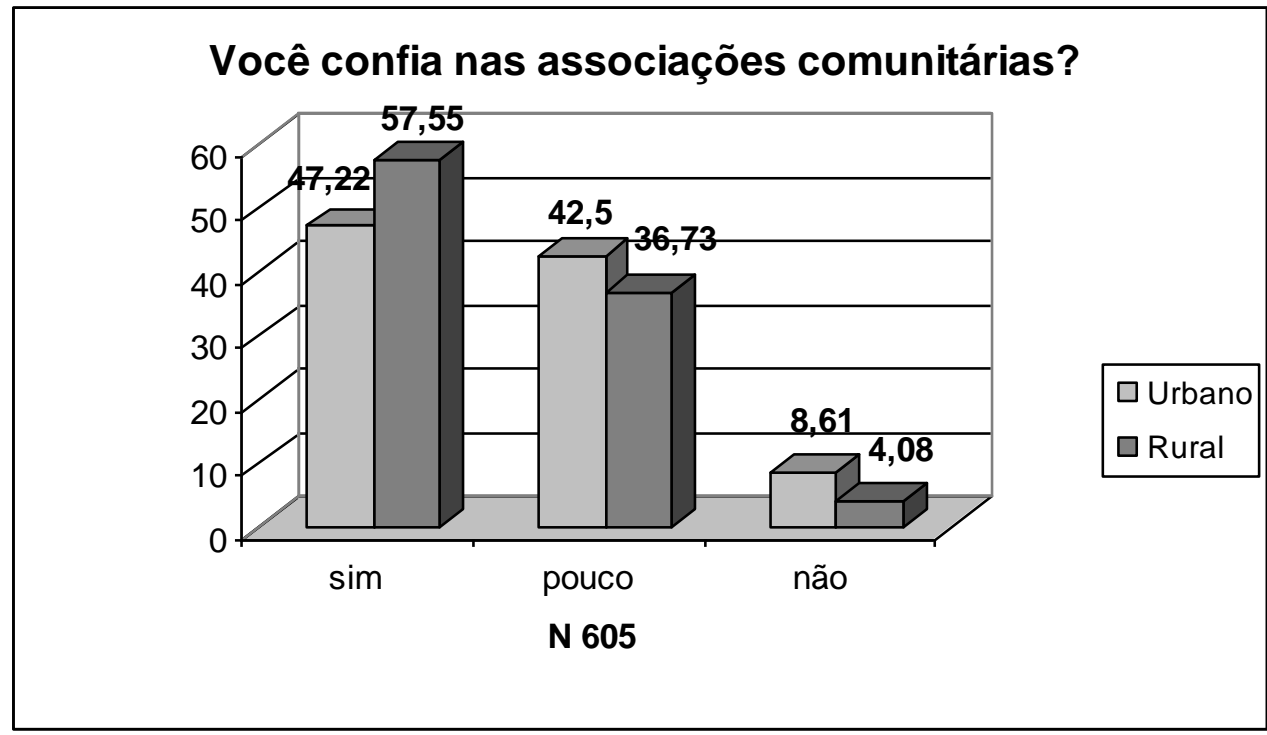

Fonte: Pase (2006).

A Figura 2 mostra que a confiança em associações comunitárias, 50\%, é bem mais generosa que a não confiança, que é de menos de $8,5 \%$, além disso, revela uma significativa diferença entre a confiança dos cidadãos urbanos, que tem um índice de $47,22 \%$, e os cidadãos rurais, que têm um índice de $57,55 \%$.

Esta informação pode ser analisada a partir da trajetória do desenvolvimento que, impulsionado no sentido da industrialização e urbanização, sinônimos de modernidade e progresso, embora tenha consolidando as desigualdades sociais e econômicas, bem como regionais, foi insuficiente para destruir as relações de reciprocidade que marcam a ocupação geográfica da região Nordeste do RS, com destaque para o espaço rural.

A confiança recíproca, revelada na Figura 2, mostra a importância da consideração do conceito de capital social. É muito difícil estabelecer normas claras e livre fluxo de informações de forma generalizada, situação menos improvável quando se define um universo de avaliação, no caso as associações.

Na mesma perspectiva, a Figura 3 mostra que a confiança materializase proporcionalmente na participação das associações comunitárias. 
Figura 3

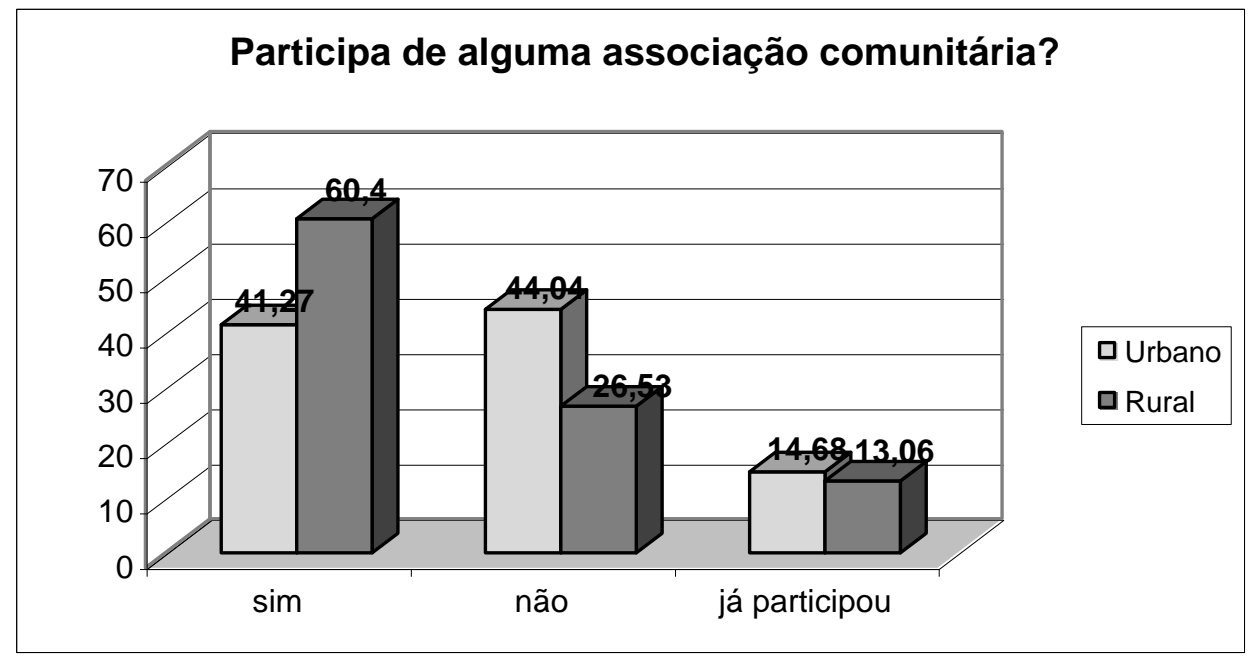

Fonte: Pase (2006).

A Figura 3 mostra uma postura no sentido de participar das associações comunitárias, com destaque para o rural que tem $60,4 \%$ de participação e o urbano com $41,22 \%$. Esta informação é comparável à utilizada por Putnam (2000), no seu estudo sobre a Itália, quando utiliza a participação nas associações voluntárias para mostrar como o Norte possui mais capital social que o Sul. César e Bandeira (2003) utilizam instrumento análogo, indicando que a dotação de capital social da metade Norte e Nordeste do Rio Grande do Sul é superior à da metade Sul e região metropolitana. A Figura 3 aprimora o estudo de César e Bandeira (2003) mostrando que a participação em associações comunitárias, no território do Corede Nordeste, é relevante chegando ao redor de $50 \%$. No entanto a informação inova ao segmentar entre os urbanos, $41,27 \%$, e entre os rurais, $60,4 \%$, revelando significativa vantagem dos últimos quanto à confiança em associações voluntárias e, portanto, em capital social.

A Figura 4 capta um dos elementos centrais para a determinação da existência de capital social: a solidariedade. 
Figura 4

\section{Você contribuiria com um projeto da comunidade que não lhe beneficiasse diretamente?}

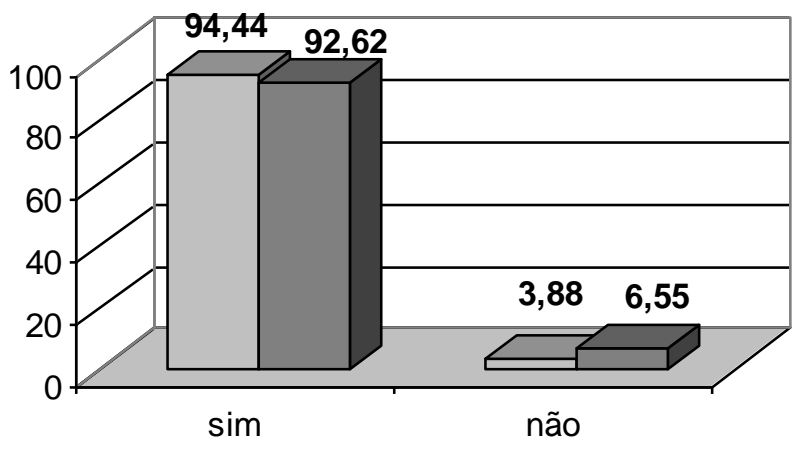

$\square$ Urbano

$\square$ Rural

N 604

Fonte: Pase (2006).

Evidencia-se grande solidariedade e colaboração entre os cidadãos da região, cujo índice supera $90 \%$ dos entrevistados, com uma sutil supremacia dos residentes no urbano.

Na Figura 5 a solidariedade e colaboração ficam ainda mais evidentes, pois verifica-se uma postura atitudinal dos cidadãos em relação à confiança perguntando-se qual a possibilidade de confiar os filhos, em caso de uma viagem de um ou dois dias, aos vizinhos, bem como se estes aceitariam assumir tal responsabilidade. 
Figura 5

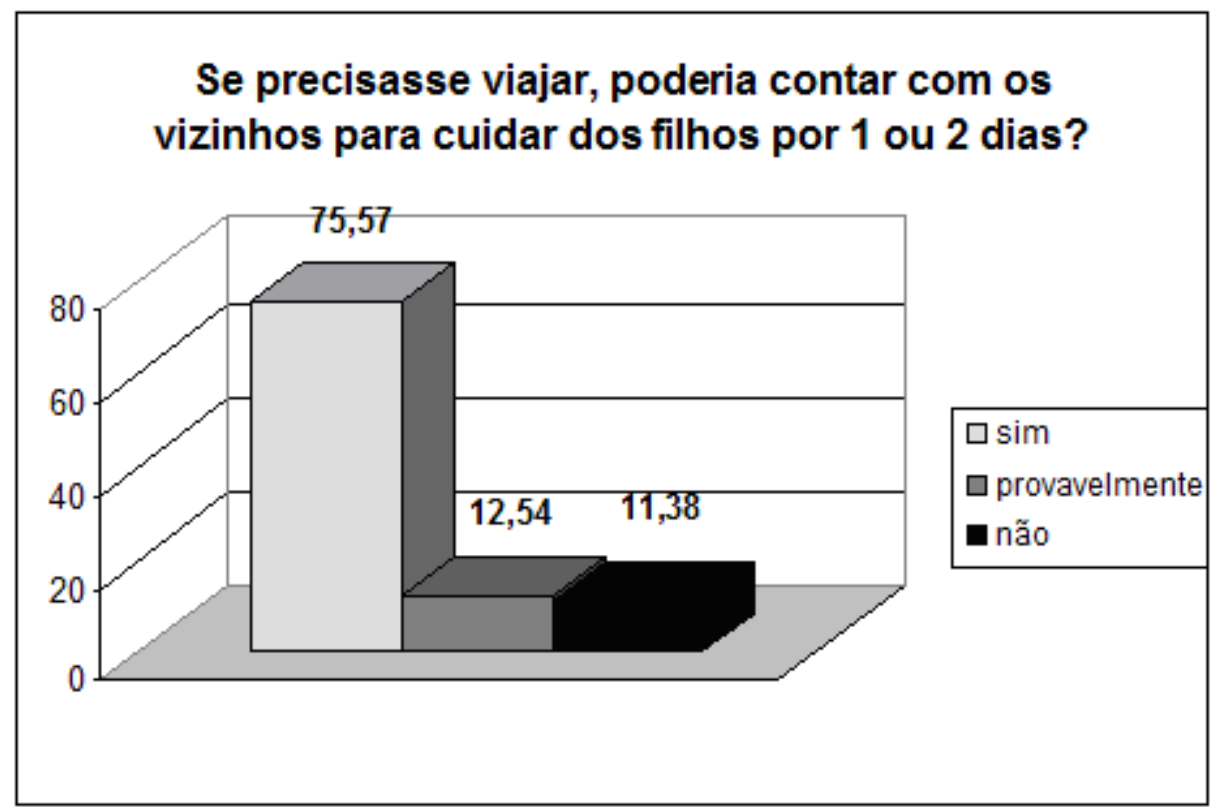

Fonte: Pase (2006).

Esta figura mostra alta confiança nos vizinhos, superando a barreira de $75 \%$ dos entrevistados, uma vez que o zelo pelos filhos é algo universal e, salvo exceções, implica em grande responsabilidade e irreparável confiança.

A Fundação de Economia e Estatística Siegfried Emanuel Heuser (FEE) calcula o Índice de Desenvolvimento Socioeconômico - IDESE para o Rio Grande do Sul, municípios e Coredes. O Corede Nordeste estava classificado em 170 lugar com um índice de 0,726 no ranking do Índice de Desenvolvimento Socioeconômico - IDESE sendo a média do Estado 0,763, ambos medianos. Essa informação diz respeito ao ranking de 2006. Atualmente o Corede Nordeste ocupa $15^{a}$ posição com um índice de 0,754 e o Estado do RS tem um índice de 0,772 . Ou seja, observa-se um melhora em ambos os territórios (FEE, 2012).

Embora a situação em 2006 fosse relativamente confortável existiam, entre os 23 municípios que compunham COREDE Nordeste naquele momento (atualmente é composto por 19), as realidades mais discrepantes.

$\mathrm{Na}$ Figura 6 far-se-á uma comparação, quanto à confiança em associações comunitárias, entre os municípios de Lagoa Vermelha e Pinhal da Serra que possuem posições antagônicas quanto ao desenvolvimento socioeconômico, mensurado pelo IDESE. O município de Lagoa Vermelha possui IDESE de 0,788 e ocupa a $19^{a}$ posição no ranking estadual, a melhor do Corede Nordeste, e Pinhal da Serra possui IDESE de 0,631 ocupando a $389^{a}$ posição no ranking estadual e a pior do Corede. 
Figura 6

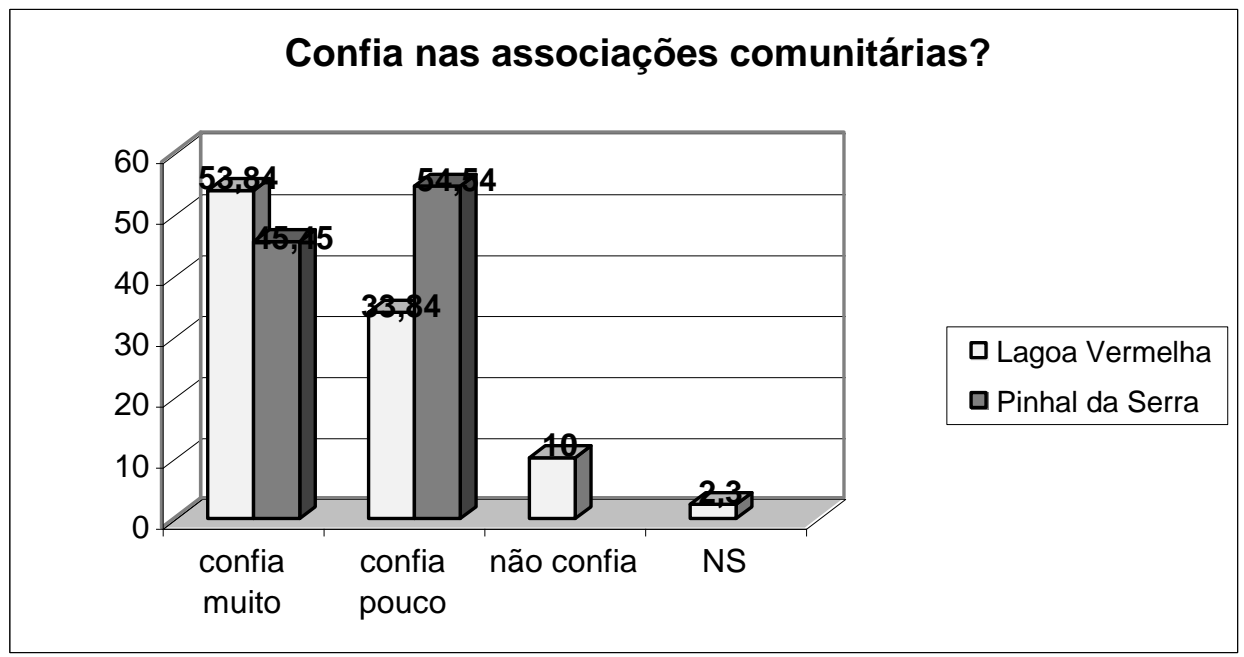

Fonte: Pase (2006).

Observa-se que no município com maior IDESE, Lagoa Vermelha, a confiança nas associações é quase $10 \%$ superior a Pinhal da Serra, que possui IDESE bastante inferior. Da mesma forma, a pouca confiança nas associações é $20 \%$ superior em Pinhal da Serra, o que sugere uma relação positiva entre o capital social e o desenvolvimento socioeconômico.

A Cooperativa de Crédito com Interação Solidária (CRESOL) utiliza o "aval solidário" com um dos mecanismos para concessão do crédito. O "aval solidário" consiste na formação de grupos de tomadores (mínimo de 3) que assumem uma responsabilidade mútua, recíproca, pelos créditos recebidos. Algumas vezes essa reciprocidade avança para a combinação de investimentos em conjunto. Esse mecanismo dispensa a necessidade de alocação de bem ou seguro como contrapartida ou garantia para obtenção de crédito ou financiamento, no entanto exige uma significativa confiança entre a instituição e os tomadores e destes entre si. Esse mecanismo é inspirado no exemplo do Banco Grameen de Muhammad Yunus (YUNUS, 2000).

A Figura 7 apresenta os níveis de confiança generalizada dos participantes da cooperativa. 
Figura 7

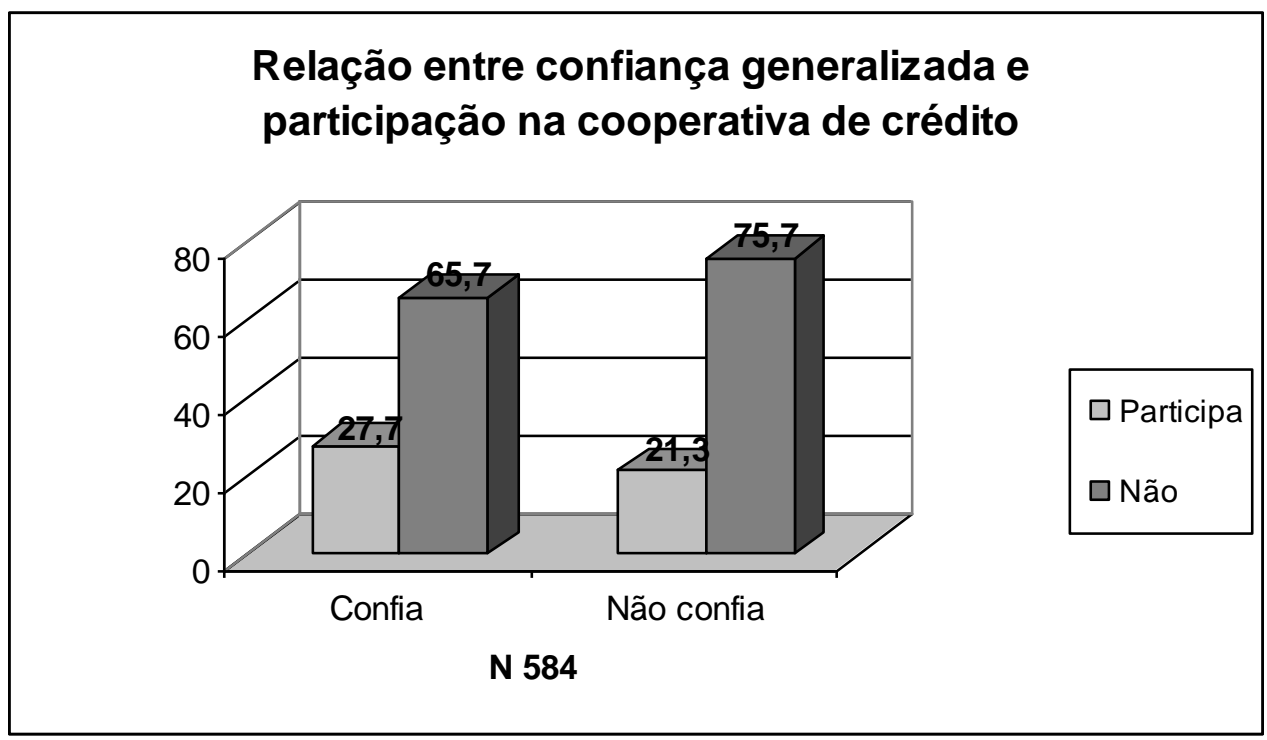

Fonte: Pase (2006).

A primeira observação é que a confiança generalizada quando segmentada entre os cooperados cresce cerca de 10\%. A Figura 1 mostra uma confiança de algo em torno de $18 \%$ e a Figura 7 mostra a confiança dos cooperados em $27,7 \%$. Esta informação revela uma superioridade significativa de confiança generalizada entre os associados da cooperativa.

Além disso, a Figura 7 mostra que entre aqueles que participam da cooperativa $27,7 \%$ confiam e $21,3 \%$ não confiam, já entre aqueles que não participam, a confiança, 65,7\%, é menor que a não confiança, 75,7\%, cuja diferença de $10 \%$ demonstra que os participantes da cooperativa possuem, ou estão sendo incentivados a desenvolver capital social.

Esta informação revela que estes cidadãos não se associam apenas motivados pelo acesso ao crédito, porém, por confiarem efetivamente nos pares. Segundo o relato dos agricultores familiares, associados à CRESOL, 0 crédito repassado pela cooperativa, é utilizado tanto como mecanismo para alavancar a produção agrícola, como também, para resolver problemas inadiáveis, como tratamento de saúde, reforma da moradia ou aquisição de eletrodomésticos, ações que incidem diretamente na melhoria da qualidade de vida. Há relatos que afirmam que o micro crédito é a única fonte de renda das famílias em anos de frustração de safra. 
A pesquisa mostra que a aposta da cooperativa de crédito no capital social é um negócio seguro, pois, segundo os dirigentes 0 índice de inadimplência fica abaixo de $1 \%$.

\section{Considerações finais}

O território do Corede Nordeste possui um estoque considerável de capital social que influencia proporcionalmente o dinamismo econômico. Os dados coletados na pesquisa de 2005 produziram informações que nos possibilitam inferir uma forte associação entre o estoque de capital social e 0 desenvolvimento socioeconômico.

O capital social parece ser essencial para o desenvolvimento endógeno que exige a cooperação permanente entre os atores regionais para criar e manter um ambiente econômico competitivo e cooperativo. O "aval solidário" é um mecanismo inovador de concessão de microcrédito, pois aceita a palavra de honra e a confiança dos amigos e/ou vizinhos, ou seja, o capital social como garantia. É uma política institucional não estatal, já que proposta e administrada de forma cooperativa e pública, pois os recursos utilizados são na sua quase totalidade obtidos nos cofres do tesouro nacional através do PRONAF.

A pesquisa revela que essa política tem um impacto direto no desenvolvimento socioeconômico, pois, incide diretamente na qualidade de vida das famílias tomadoras. Além disso, impulsiona novos arranjos organizativos como a formulação de associações para aquisição de máquinas, construção de agroindústria, aquisição de insumos estimulando o aprimoramento do capital social, base do mecanismo do "aval solidário".

Não obstante, existe toda uma literatura que demonstra que o crescimento econômico ocorre como resultado da intervenção de atores econômicos e/ou de políticas públicas, como demonstram as teorias da modernização. No caso da agricultura, a ideologia da "modernização conservadora" modificou a matriz produtiva, investindo fortemente em tecnologia poupadora de mão de obra e exigente em grandes volumes de recursos, impulsionando um processo de desenvolvimento concentrado e excludente.

As dinâmicas econômicas que desconsideram 0 tecido social preexistente têm grandes chances de serem excludentes e concentradoras de renda e riqueza, como demonstra o caso brasileiro que ampliou a concentração da terra e da renda exportando o desenvolvimento, como no caso da produção de cereais que, em grande parte, exporta produtos in natura que são transformados em outras regiões e/ou países, onde ocorre agregação de valor.

A literatura sobre a importância do capital social para as estratégias de desenvolvimento tem se avolumado rapidamente nesses 10 anos (desde o 
seminário de 2005 até hoje) e, ao que parece, tem sido compreendido por alguns setores do Estado brasileiro que tem proposto iniciativas de articulá-lo explicitamente em algumas políticas públicas. Exemplo disso é o Programa Desenvolvimento Sustentável de Territórios Rurais - PDSTR, criado em 2003 pelo Ministério do Desenvolvimento Agrário (MDA), através da Secretaria de Desenvolvimento Territorial (SDT), cujo objetivo é promover e apoiar as iniciativas da sociedade civil e dos poderes públicos nos territórios rurais incorporados ao programa, visando o desenvolvimento sustentável, com redução das desigualdades regionais e sociais e integração das dinâmicas territoriais ao processo de desenvolvimento nacional (MDA, 2005).

O capital social aparece como um dos quatro eixos aglutinadores que articulam metodologicamente o programa: fortalecimento da gestão social; fortalecimento das redes sociais de cooperação; dinamização econômica; e articulação de políticas públicas.

O segundo eixo é explicitado da seguinte forma:

o fortalecimento das redes sociais de cooperação, derivadas da evolução do "capital social", que consolidam as condições objetivas necessárias aos processos de desenvolvimento, sendo enfatizada a ampliação e qualificação de competências organizacionais e pessoais, das relações solidárias e complementares, possibilitando uma maior coerência e adesão dos atores locais e a otimização das iniciativas individuais e coletivas (RECH e PASE, 2010, p. 5-6, grifo meu).

Em trabalho analisando o PDSTR no território Zona Sul do Estado/RS no período 2004-2010 (RECH e PASE, 2010), percebe-se que o programa vem provocando uma mudança na cultura política regional e na democratização do espaço e dos bens públicos, proporcionando espaços de participação política para grupos historicamente marginalizados. Mesmo que exista uma intensa disputa por recursos públicos e/ou implementação de obras, o território tem se tornado um espaço de expressão política e de aprendizado de participação cidadã, alargando a cidadania política dos que o integram, cuja ocorrência tem sido possibilitada pela consideração do capital social como variável inclusiva que empodera os grupos sociais historicamente excluídos como os agricultores familiares e assentados de reforma agrária, os pescadores artesanais e, mais recentemente, representantes das comunidades quilombolas, que até então estavam alijados dos processos de decisão e implementação de políticas públicas.

Resta evidente a importância do capital social para as estratégias de desenvolvimento, particularmente quando analisado numa região com significativos déficits de desenvolvimento como a metade Sul do Rio Grande do Sul. 
Isto posto, é mister dar continuidade a estudos dessa natureza que preocupem-se em analisar e avaliar a importância do capital social enquanto característica agregada na sociedade, bem como, variável que pode ser impulsionada a partir de políticas públicas intencionadas.

Hemerson Luiz Pase é Doutor em Ciência Política. Professor do Programa de Pós-Graduação em Ciência Política (PPGCPol) e coordenador do Núcleo de Estudos em Política Públicas (NEPPU) da Universidade Federal de Pelotas.

E-mail: hlpase@yahoo.com.br

\section{Referências}

ALONSO, José A.; BANDEIRA, Pedro S. Crescimento Inter-regional no Rio Grande do Sul, nos anos 80. In: ALMEIDA, Pedro F. C. A economia gaúcha nos anos 80: Uma tragetória regional no contexto da crise brasileira. Porto Alegre: FEE, 1990. p. 67-130. (tomo 1).

BAQUERO, Marcello. Construindo uma outra sociedade no Brasil. O papel do capital social na estruturação de uma cultura política participativa. Revista Sociologia e Política, Curitiba, s/ v. n. 21, p. 83-108, nov. 2003.

BAQUERO, Marcello; PRÁ, Jussara Reis. Matriz histórico-estrutural da cultura política do Rio Grande do Sul e padrões de participação política. Cadernos de Ciência Política - PPG em Ciência Política da UFRGS, Porto Alegre, s/ v. n. 3, 1995. (Série Pré-edições).

BOURDIEU, Pierre. Le Capital Social: Notes Provisoires. Actes de la Recherche en Sciences Sociales, Paris, v. 31, p. 2-3, jan. 1980.

CESAR, Benedito T.; BANDEIRA, Pedro S. Caracterização do Rio Grande do Sul: desenvolvimento regional, cultura política e capital social. In: SCHNEIDER, Flávio Miguel; LUBECK, Elisa (Org.). Programa de Desenvolvimento Integrado e Sustentável da Mesorregião Metade Sul. Santa Maria: Pallotti, 2003. p. 41-93.

COLEMAN, James S. Foundations of Social Theory. Cambridge: Harvard University Press, 1990.

ESTADO DO RIO GRANDE DO SUL. Atlas socioeconômico do Rio Grande do Sul. 2011. Disponível em: <http://www.scp.rs.gov.br/atlas/atlas.asp?menu= 26>. Acesso em: 20 jan. 2012. 
EVANS, Peter. Government Action, Social Capital and Development: Reviewing the Evidence on Synergy. World Development, Amsterdam, v. 24, n. 6, p. 1119-1132, jun. 1996.

FEE. Fundação de Economia e Estatística. Estatísticas FEE. 2012. Disponível em: <http://www.fee.tche.br/sitefee/pt/content/estatisticas/pg_idese_corede s_classificacao_idese.php>. Acesso em: 20 jan. 2012.

GEHLEN, Ivaldo; MELO, José Luiz Bica de. A dinâmica da Agricultura no Sul do Brasil: realidade e perspectivas. São Paulo em Perspectiva, São Paulo, v. 11, n. 2, p. 99-108, abr.-jun. 1997.

HOLANDA, Sérgio Buarque de. Raízes do Brasil. São Paulo: Companhia das Letras, 1995.

MDA. Ministério do Desenvolvimento Agrário. Referências para uma Estratégia de Desenvolvimento Rural Sustentável no Brasil. Brasília: MDA/SDT CONDRAF, 2005.

NAVARRO, Zander Soares. Desenvolvimento rural no Brasil: os limites do passado e os caminhos do futuro. Estudos Avançados, São Paulo, v. 15, n. 43, p. 83-100, set.-dez. 2001.

PASE, Hemerson Luiz. Democracia Participativa e Desenvolvimento: a influência do orçamento participativo no desenvolvimento rural de Floriano Peixoto. 2001. 170 f. Dissertação (Mestrado em Desenvolvimento Rural) Programa de Pós-Graduação em Desenvolvimento Rural, UFRGS, Porto Alegre, 2001.

. Capital Social e Desenvolvimento Regional: a importância do capital social no desenvolvimento territorial do COREDE Nordeste. 2004. 20 f. Projeto de Pesquisa - UERGS/FAPERGS, Sananduva, 2004.

. Capital social e desenvolvimento regional: a importância do capital social no desenvolvimento territorial do COREDE Nordeste. 2006. $123 \mathrm{f}$. Relatório Final - UERGS/FAPERGS, Sananduva, 2006.

PRADO JUNIOR, Caio. História Econômica do Brasil. 30.ed. São Paulo: Brasiliense, 1984.

PUTNAM, Robert D. Comunidade e democracia: a experiência da Itália moderna. 2. ed. Rio de Janeiro: Editora FGV, 2000. 
PUTNAM, Robert; GOSS, Kristin. Introduction. In: PUTNAM, Robert (Org.). Democracies in flux. The evolution of social capital in contemporary societies. New York: Oxford University Press, 2002. p. 3-21.

QUEIROZ, Maria I. P. O coronelismo numa interpretação sociológica. In: FAUSTO, Boris. História Geral da Civilização Brasileira. São Paulo: Difel, 1975. Tomo 3, v. 1, p. 155-190.

RECH, Carla M.; PASE, Hemerson Luiz. O Território Zona Sul do Estado/RS: um campo fértil à democracia. In: Conferência Nacional de Políticas Públicas Contra a Pobreza e a Desigualdade. Natal, 1., 2010. Disponível em: <http://cchla.ufrn.br/cnpp/pgs/anais/Arquivos>. Acesso em: 03 abr. 2012.

SEN, Amartya. Desenvolvimento como liberdade. São Paulo: Companhia das Letras, 2000.

SINGER, PAUL. Desenvolvimento econômico e evolução urbana. 2. ed. São Paulo: Cia Editora Nacional, 1977.

SOARES, Maria Susana Arrosa. (Re)Pensando a Modernidade Latinoamericana. Cadernos de Sociologia, Porto Alegre, v. 5, n. 5, p. 24-31, 1993.

VEIGA, José Eli da. O Brasil Rural ainda não encontrou seu eixo de desenvolvimento. Estudos Avançados, São Paulo, v. 15, n. 43, p. 101-119, set.-dez. 2001.

WEBER, Max. Ética protestante e o "espírito" do capitalismo. São Paulo: Companhia das Letras. 2005.

YUNUS, Muhammad. O Banqueiro dos pobres. São Paulo: Editora Ática, 2000. 